\title{
La acción civil en el Nuevo Proceso Penal
}

\author{
GONZALO DEL RÍO LABARTHE*
}

\begin{abstract}
SUMARIO: INTRODUCCIÓN.- I. NATURALEZA DE LA ACCIÓN CIVIL EN EL PROCESO PENAL.- II. EL NUEVO CÓDIGO PROCESAL PENAL DE 2004.III. CAMBIO DE HÁBITO.
\end{abstract}

\section{INTRODUCCIÓN}

Este artículo pretende analizar algunas de las reglas del Nuevo Código Procesal Penal de 2004 (NCPP 2004, en adelante) vinculadas a la regulación del ejercicio de la acción civil en el proceso penal.

Se intenta demostrar que el NCPP «ataca» una vieja confusión vinculada a la idea de que la acción civil en el proceso penal deriva del delito, interpretación que conduce a un supuesto interés público o de la sociedad en el pago de la reparación civil o en la reparación del daño que distorsiona, seriamente, su tratamiento procesal.

El NCPP ubica en su real dimensión la participación del MP en el ámbito de la acción civil (artículo 1 LOMP, artículo 11 NCPP) y establece que su actividad, en el ejercicio de esa pretensión, tiene un carácter esencialmente sustitutivo. Además, es un instrumento normativo que reafirma la idea de que la acción civil ejercitada en el proceso penal es privada y dispositiva.

Por otro lado, el nuevo proceso penal permite que se ordene el pago de la reparación civil, incluso en aquellos supuestos en los que no existe una sentencia de condena penal; ello involucra una renuncia al viejo modelo de accesoriedad restringida. Además, ubica la acumulación heterogénea de pretensiones en el contexto que debe ocupar, que es el de la celeridad procesal.

Este cambio en la concepción del ejercicio de la acción civil en el proceso penal permite entender que la condición de perjudicado y, por tanto, la capacidad que tiene este para constituirse en actor civil no debe analizarse desde la perspectiva de la estructura del tipo delictivo en tanto ella no tiene por qué condicionar la existencia o la inexistencia de un daño. Mucho menos si se tiene en cuenta que hoy el NCPP admite condenar al pago de una reparación civil aun en la sentencia absolutoria y en el auto de sobreseimiento. 
Finalmente, un cambio de esta naturaleza en la visión que se tiene de la acción civil acumulada al proceso penal también debería contribuir a un tratamiento más coherente del sistema, en la identificación del daño y el monto indemnizable, así como a determinar cuál es el rol que debe cumplir el actor civil en el proceso penal.

\section{NATURALEZA DE LA ACCIÓN CIVIL EN EL PROCESO PENAL}

Montero Aroca plantea, con acierto, la confusión que existe en la doctrina en torno a lo que debe entenderse como objeto del proceso penal, y que esa falta de claridad se origina en el mismo punto de partida al mezclar la acción penal con la acción civil y, consiguientemente, el proceso penal y civil que dan lugar a cada una de aquellas.

Mantiene que la confusión proviene de haberse sostenido con reiteración que de todo delito o falta nace una acción penal para el castigo del culpable, que puede nacer también una acción civil para el resarcimiento del perjudicado y que toda persona responsable de un delito o de una falta lo es también civilmente, por lo que hablar de obligaciones civiles que nacen de delitos o faltas no es ajeno a esta confusión ${ }^{1}$.

En realidad, debe partirse de la idea de que la responsabilidad civil que se exige en el proceso penal no deriva de la comisión de un hecho delictivo: el delito tiene como consecuencia una pena; el ilícito civil, una consecuencia de esa naturaleza. No hay dos tipos de responsabilidad civil por el hecho de que una de ellas dimane de un ilícito civil sin repercusión penal y otra lo sea de un hecho que a la vez puede ser considerado como delito ${ }^{2}$.

La respuesta judicial a la acción civil nunca lo es de carácter penal, sino civil. Consiste en una restitución, en una reparación o en una indemnización. La responsabilidad civil nace porque el hecho produce el daño o porque implica un menoscabo patrimonial de la víctima ${ }^{3}$.

En consecuencia, lo que interesa $-\mathrm{o}$ lo que debe interesar- al actor civil es que exista un daño reparable, no que el hecho del que deriva sea delito. Un entendimiento erróneo de esta cuestión es lo que ha llevado a que, durante muchos años, en el Derecho comparado, la resolución de la cuestión civil se vincule (siempre) a la emisión de una sentencia condenatoria (accesoriedad restringida).

1 Montero Aroca, J. Proceso penal y libertad. Ensayo polémico sobre el nuevo proceso penal. Navarra: Thomson Civitas, 2008, p. 323.

2 Asencio Mellado, J.M. La acción civil en el proceso penal. El salvataje financiero. Lima: ARA Editores, 2010, pp. 42-43.

3 Cortés Domínguez V. y MoReno Catena. Derecho procesal penal. Segunda edición. Valencia: Tirant lo Blanch, 2005, p. 165. 
Sin embargo, la acción civil no es accesoria de la penal. Lo que existe es una simple acumulación de pretensiones cuyo fundamento radica en la economía procesal. El actor civil no cuenta con legitimación alguna para sostener, aunque sea indirectamente, la acción penal y menos para, sin ostentar interés civil, instar a la continuación del proceso penal ${ }^{4}$.

La acumulación de la acción civil al proceso penal responde, sencillamente, a un supuesto de acumulación heterogénea de pretensiones, con fines procesales estrictos. Esta tendencia encuentra un beneficio en el hecho de que, con el menor desgaste posible de jurisdicción, se pueda reprimir el daño público causado por el delito y reparar el daño privado ocasionado por el mismo hecho.

Además, se considera beneficioso que el perjudicado tenga a su disposición dos vías para procurar la reparación de su agravio ${ }^{5}$. En cierto sentido, favorece la unidad de respuesta del ordenamiento jurídico, si se tiene en cuenta que la determinación del hecho por aquel orden jurisdiccional encargado de establecer la existencia o inexistencia del delito y la determinación de un supuesto de responsabilidad extra contractual se ubican en un mismo sujeto (el juez penal), lo que permite un importante nivel de satisfacción en el plano de la coherencia de la potestad jurisdiccional.

En el Perú, la confusión antes apuntada es patente. Su origen se ubica en el artículo $92 \mathrm{CP}$ cuando establece que la reparación civil se determina conjuntamente con la pena. A partir de un análisis estricto de esta norma, y frente a la ausencia de una normativa que regule detalladamente el ejercicio de la acción civil en el CPP 1940, durante muchos años se ha interpretado la acción civil del proceso penal desde la perspectiva de una estricta accesoriedad restringida.

Sobre esta base, nuestro sistema jurídico ha entendido que la acción civil solo puede ser declarada en un proceso penal si, además, existe una sentencia condenatoria que acredita la responsabilidad penal por el hecho cometido.

Núñez explica esta tendencia a partir del pensamiento de los penalistas adeptos a la escuela positiva, quienes incurrieron en el error de considerar que la reparación del daño patrimonial causado por el delito —o por el hecho que, además, es considerado delito- es un asunto de Derecho público, y que como tal debía ser tratado por el legislador. Esto condujo a confundir la reparación civil con una enmienda que no está solo destinada a satisfacer el interés que tiene el damnificado en que se repare el

4 Asencio Mellado, J.M. La acción civil... Ob. cit., pp. 44-46. El artículo 388.1 NCPP dispone que el abogado del actor civil argumentará sobre el agravio que el hecho ha ocasionado a su patrocinado, también puede demostrar el derecho a la reparación que tiene su defendido y destacar la cuantía en que estima el monto indemnizatorio, y puede solicitar la restitución del bien, si esto es aún posible, o el pago de su valor. Por su parte, el artículo 388.2 permite al abogado del actor civil esclarecer con toda amplitud los hechos delictuosos, pero siempre que sean relevantes para la imputación de la responsabilidad civil, está prohibido de calificar el delito. Finalmente, el artículo 105 dispone que al actor civil no le está permitido pedir sanción.

5 NúÑEZ, R.C. La acción civil en el proceso penal. Córdoba: Marcos Lerner, p. 26.

LA ACCIÓN CIVIL EN EL NUEVO PROCESO PENAL 
daño que le ha causado el delito, sino que obedece, también, de manera principal, a la idea de tranquilizar a la sociedad al darle la seguridad de que el delincuente reparará el daño privado ocasionado por su delito. Es esta una de las razones en virtud de la cual se establece que la reparación puede ser perseguida, de oficio, por el $\mathrm{MP}^{6}$.

Por esta razón, otro origen, si se quiere «normativo», de la confusión se ubica también, en el artículo 1 LOMP cuando establece que el MP es el organismo autónomo del Estado que tiene como funciones principales, entre otras, la persecución del delito y la reparación civil. Esta norma condujo a que, durante mucho tiempo, fuera obligatorio para el MP que, cuando promoviera la acción penal, debiera ejercer, acumulativa y obligatoriamente, la acción civil ex delicto.

Prueba de la confusión apuntada se ubica en la propia doctrina nacional que llega a establecer que son tres los intereses en juego en el proceso penal: el interés de la sociedad en que se aplique la pena, el interés del particular en que se repare el daño y el interés de la propia sociedad en la reparación del daño. Se sostiene incluso que el interés de la sociedad en la reparación del daño es el que fundamenta y legitima al Ministerio Público para buscar y solicitar la reparación del daño en la investigación preparatoria o en la acusación correspondiente?

Esta confusión parte de una comprensión equivocada de la legitimación procesal activa del MP para el ejercicio de la acción civil. San Martín Castro señala con acierto que debe diferenciarse la naturaleza civil de la institución con la legitimación activa que permite introducir la pretensión en el proceso penal. Es esta - la que regula el artículo 1 LOMP — una legitimación extraordinaria, dado que el MP no es —ni lo es la sociedad - el titular del Derecho subjetivo privado, sino que por disposición de la ley actúa en nombre propio, pero afirmando derechos subjetivos ajenos ${ }^{8}$. Esta es la única forma que permite compatibilizar la participación del MP en el ejercicio de la acción civil y su naturaleza eminentemente privada.

Sin embargo, en el sistema procesal anterior, si bien se siguió la postura de una legitimación extraordinaria, no se entendió que esta además debe serlo por sustitución? . Ello condujo a que, cuando el agraviado se constituye en parte civil, el fiscal insista — - entiende en aplicación del artículo 1 LOMP — en solicitar una reparación civil específica que «COincide», en muchos casos, con la pretensión del actor. Así se plantean dos pretensiones distintas cuando el único titular del Derecho subjetivo alegado es el perjudicado. 
Si el MP actúa en interés de la víctima —al proteger ese interés privado- no se explica por qué es necesario que insista en introducir una pretensión cuando el agraviado, constituido en actor civil, está ejerciéndola en el proceso. La participación del MP en el ámbito descrito por la LOMP, por su propia naturaleza, se dirige al «desamparo», a los casos en los que el perjudicado — por la razón que fuere — no se ha constituido en actor civil en el proceso penal. No tiene sentido la participación del fiscal en la acción civil cuando el agraviado formaliza su pretensión y participa en el proceso ${ }^{10}$.

Lo esencial en el ejercicio de la acción penal es que se realice en representación del Estado para lograr fines de naturaleza pública, y esto lo puede hacer tanto un órgano público como un particular (acción privada). Pero si la naturaleza de la acción civil se quiere mantener incólume, la legislación no puede atribuir la titularidad de ella a un órgano público o a cualquier particular para que actúen de motu propio y con independencia de la voluntad del damnificado ${ }^{11}$.

Por ello, este estudio no rechaza, de plano, la participación del MP; se debe entender que este actúa en el proceso penal por sustitución. Participa representando un interés privado y, por tanto, no puede actuar con independencia de la voluntad del perjudicado. Incluso, como se verá, su participación cesa definitivamente cuando el actor civil se apersona al proceso.

En este orden de ideas, hasta aquí han sido explicados los dos principales problemas que enfrenta una concepción de la acción civil en el proceso penal desde la perspectiva de una accesoriedad restringida: concretamente, se entiende que la reparación civil solo puede ser decretada si existe una previa sentencia condenatoria. Por otro lado, concebir la participación del MP en el ejercicio de la acción civil como obligatoria es consecuencia de un falso entendimiento de la pretensión civil como un «interés público de la sociedad» y de una reparación civil que se asimila a un acto punitivo. Estos problemas son, en gran parte, solucionados por la nueva regulación del NCPP 2004.

\section{EL NUEVO CÓDIGO PROCESAL PENAL DE 2004}

\section{II.1. La participación del MP y la naturaleza privada de la acción civil}

El NCPP 2004 regula el ejercicio de la acción civil en el proceso penal en la sección II del Libro Primero (Disposiciones Generales). Esta sección involucra, probablemente, la modificación más importante en

10 Véase DEL Río LABARTHE, G. La etapa intermedia en el nuevo proceso penal acusatorio. Lima: ARA, 2010, p. 69.

11 NúÑEZ, R.C. La acción civil... Ob. cit., p. 21. 
torno a la posibilidad de ejercer la acción civil en el proceso penal de los últimos tiempos.

El artículo 11 NCPP establece que el ejercicio de la acción civil derivada del hecho punible corresponde al MP y, especialmente, al perjudicado por el delito. Si el perjudicado se constituye en actor civil, cesa la legitimación del MP para intervenir en el objeto civil del proceso.

En tal virtud, el NCPP mantiene la legitimación extraordinaria del MP, pero siempre que el titular de ese o de esos derechos no introduzca o esté dispuesto a introducir su pretensión. La regulación no admite dudas; queda claro que el MP actúa solo en interés de la víctima. Si no fuera así, el cese de su participación no tendría sentido.

Por ello, el NCPP no rechaza la participación del MP, aunque sí la ubica en su real dimensión como una legítima manifestación del ejercicio de la función fiscal en defensa de la legalidad (artículo 159 de la Constitución) y realizada al amparo del interés de la víctima, cuyos derechos también deben estar garantizados en el ámbito del proceso penal.

La naturaleza absolutamente privada de la acción civil acumulada al proceso penal se aprecia claramente en la regulación de los artículos 12, 13 y 14 NCPP. El artículo 12.1 otorga libertad al perjudicado por el delito para elegir entre el proceso penal o el Orden Jurisdiccional Civil al ejercer su pretensión. La única regla que establece el Código es la imposibilidad de que exista un concurso de pretensiones: la pretensión es alternativa en el sentido de que, al optar por alguna de ellas, no podrá deducir su pretensión civil en otra vía jurisdiccional. Sobre dicha línea, el NCPP también permite que el perjudicado acuda al Orden Jurisdiccional Civil con el propósito de ejercer su pretensión en aquellos casos en los que el proceso penal se suspenda por alguna consideración legal (12.2 NCPP).

Por otro lado, el artículo 13 NCPP permite que el actor civil desista de su pretensión de reparación civil hasta antes del inicio de la etapa intermedia. Ello no perjudica su derecho a ejercerlo en la vía de proceso civil. Finalmente, el artículo 14 consiente que la acción civil sea objeto de transacción. El artículo 14.2 exige que, una vez que la transacción se formalice ante el juez de la investigación preparatoria — transacción a la que el MP no puede oponerse-, el fiscal se abstenga de solicitar reparación civil en su acusación; así se descarta un supuesto interés público o social en la reparación del daño ocasionado por un hecho que, a su vez, es o puede ser considerado como delito.

En tal virtud, esta normativa reafirma la idea de que la acción civil ejercitada en el proceso penal es privada y por ello dispositiva, y esto supone que la regla general, lógica y coherente con el principio dispositivo sea que el perjudicado muestre su voluntad de que en el proceso penal sea enjuiciada la acción civil. Además, la sentencia que se dicte durante el 
proceso ha de ser congruente con las peticiones de las partes civiles, en tanto que lo dispuesto en las leyes procesales civiles es de aplicación ${ }^{12}$.

\section{II.2. Acción civil y sentencia condenatoria}

Sin lugar a dudas, la modificación más importante del NCPP en el ámbito de la acción civil incorporada al proceso penal se ubica en el artículo 12.3 NCPP, donde se establece que «la sentencia absolutoria o el auto de sobreseimiento no impedirá[n] al órgano jurisdiccional pronunciarse sobre la acción civil derivada del hecho punible válidamente ejercida, cuando proceda».

Una prueba del rezago de la confusión explicada en este artículo se plantea en el ámbito de la propia redacción de esta norma, incluso cuando constituye un giro sustancial en la interpretación del ejercicio de la acción civil. Como es obvio, luego de la sentencia absolutoria o el auto de sobreseimiento, no se puede calificar, como hace el artículo 12.3 NCPP, al hecho como «punible». Se debió utilizar la frase «acción derivada del hecho que constituye el objeto del proceso» o una similar.

La advertencia de este error de redacción es una clara muestra de que, precisamente, no se está ante una acción civil derivada de un hecho punible; como ya se dijo, la responsabilidad civil que se exige en el proceso penal no deriva de la comisión de un hecho delictivo. El delito tiene como consecuencia una pena; el ilícito civil, una consecuencia de esa naturaleza.

Superado el error en la interpretación, esto es precisamente lo que regula el artículo 12.3 NCPP: que se descarte la presencia de responsabilidad penal, vía auto de sobreseimiento o mediante una sentencia absolutoria, no significa que la jurisdicción deba renunciar a la reparación de un daño que evidentemente se ha producido como consecuencia del hecho que constituye el objeto del proceso, incluso cuando ese hecho no puede ser calificado como un ilícito penal.

Si la acumulación heterogénea de pretensiones en el proceso penal se justifica en razones estrictamente procesales, vinculadas a la celeridad procesal y a la unidad de respuesta del ordenamiento jurídico, entonces es evidente que no tiene sentido que la sentencia absolutoria o, en su caso, el auto de sobreseimiento impliquen una renuncia a la posibilidad de pronunciarse sobre el daño que puede haber sido perfectamente comprobado durante la sustanciación del proceso.

Mucho menos que la «imposibilidad» de emitir un pronunciamiento en ese extremo obligue al perjudicado a iniciar otra acción en otro orden jurisdiccional civil para que la misma jurisdicción —que es única- se pronuncie, por estrictas razones de especialidad, luego de 
haber sustanciado dos procesos distintos sobre la base de un mismo hecho. Esto involucra una reproducción de acciones innecesarias y es consecuencia de una errada concepción: al no asumir que aquello es una acumulación heterogénea de acciones, considera equivocadamente que el juez penal «solo» puede pronunciarse con relación a la acción civil frente a la existencia de responsabilidad penal, lo que no guarda sentido alguno con la naturaleza de la acumulación. Esta decisión, que es la que actualmente regula el CPP 1940, no guarda sentido con la celeridad procesal como objetivo y con la concepción de la jurisdicción única.

Desde luego, si el sobreseimiento o la absolución se amparan en la inexistencia del hecho que conforma el objeto procesal, es imposible condenar al pago de una reparación civil en alguna de esas resoluciones. Por inexistencia del hecho, cabe entender solo dos supuestos: (a) cuando esté probado que el hecho no ha sucedido; y (b) cuando resulte probado que el acusado no fue el autor del hecho criminal, pues se entiende que respecto de este el hecho no ha existido ${ }^{13}$. Porque, si bien es cierto que hoy no es necesario acreditar la responsabilidad penal como conditio sine qua non de la declaración de la existencia de responsabilidad civil, también es cierto que la declaración acerca de la existencia del hecho — que no es lo mismo- evidentemente condiciona no solo la posibilidad de imponer una pena, sino también la de obligar al responsable al pago de un concepto indemnizatorio.

Pese a ello, en los supuestos de atipicidad, no punibilidad, presencia de una causa de justificación y, en algún caso, algunas reglas de prescripción no siempre extinguen la acción civil porque, precisamente, existe un daño de carácter civil que, si bien no acredita la presencia de un delito, sí comprueba la necesidad de una indemnización por el daño causado.

Un supuesto clásico que se presenta en muchas ocasiones viene dado por el hecho de que es común que se denuncie a título de estafa lo que en sentido estricto constituye un incumplimiento contractual en el que no media la presencia de dolo o un engaño que configure el tipo delictivo. Sin duda, en este caso se debe decretar el sobreseimiento o la absolución por atipicidad; sin embargo, si se verifica el incumplimiento, el órgano jurisdiccional está obligado a dictar una indemnización por daños y perjuicios en la resolución de sobreseimiento o en la propia sentencia absolutoria.

También es posible que se dé inicio a un proceso penal en el que se imputa a determinada persona un delito de daños y, sin embargo, es posible también que en ese procedimiento se establezca que el daño existe, pero que fue ocasionado de forma negligente. El NCPP también permite que 
el órgano jurisdiccional obligue al pago de una indemnización por el daño causado aun cuando es imposible sancionar penalmente al responsable por causal de atipicidad, en tanto nuestro CP no regula la figura de daños culposos. Cosa distinta es que en el proceso penal se demuestre la inexistencia del daño o que este no es imputable al procesado, ni a título de dolo ni a título de culpa. El primer caso se corresponde con un supuesto de inexistencia de responsabilidad penal; el segundo, con un supuesto de inexistencia del hecho o, si quiere, de inexistencia del hecho que ha constituido —en tanto hipótesis— el objeto procesal.

\section{CAMBIO DE HÁBITO}

Hasta aquí hemos analizado el problema central de la acción civil acumulada al proceso penal, que se ubicaba en una malentendida accesoriedad restringida, hoy superada por la nueva regulación del NCPP que, además, regula con claridad su naturaleza privada y por tanto dispositiva.

A ello se suma el hecho de concebir la participación del MP en la acción civil como una de carácter sustitutivo y, por ende, subsidiario, sin que ello signifique comprender dicha participación como una integrada en el interés público. El fiscal nunca actúa en este extremo de motu propio y con independencia de la voluntad del perjudicado: se está, simplemente, ante una legitimación procesal activa que permite introducir la pretensión en el proceso, una legitimación extraordinaria que permite al MP actuar en nombre propio, pero afirmando derechos subjetivos ajenos.

Por último, también se ha analizado como la superación de una concepción de la accesoriedad restringida: se ubica en el hecho de que la sentencia penal condenatoria no es más una conditio sine qua non de la declaración de responsabilidad civil en el proceso penal, en tanto ella puede ser declarada incluso en la sentencia absolutoria o en el auto de sobreseimiento (12.3 NCPP).

Pero existen otros dos problemas fundamentales que son bastante antiguos en la doctrina jurisprudencial y que considero que también son consecuencia, aunque de manera menos directa, de la confusión que ha sido objeto de estudio en este análisis. En nuestro sistema procesal penal no en pocas ocasiones se activa el análisis de la condición de agraviado desde la estricta perspectiva de la tipicidad penal, como si solo ella fuera de capaz de indicarnos quién es el sujeto perjudicado como consecuencia de la acción u omisión que conforma el objeto del proceso.

Analicemos algunos ejemplos:

1. Juan conduce un vehículo en absoluto estado de ebriedad, colisiona contra el garaje de Pedro y lo destroza.
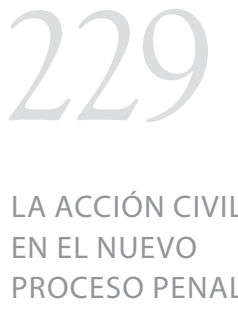
2. En un concurso público de contratación para la adquisición de bienes para elEstado existe una concertación entre los funcionarios encargados de otorgar la buena pro a uno de los postores, la empresa Concertando. Se entiende que tal infracción causa un perjuicio al erario público o al correcto desenvolvimiento de la administración pública; sin embargo, existe un postor, Ultramar, que invirtió tiempo y dinero en su propuesta y que se encuentra claramente perjudicado por el hecho que es objeto del proceso en lo que podría constituir un supuesto de daño emergente.

3. Andrés comete un delito de fraude procesal en un proceso civil originado en virtud de una demanda interpuesta contra Santiago por obligación de otorgar suma de dinero. Si bien la conducta de Andrés, desde la perspectiva del Derecho penal, afecta el normal funcionamiento de la administración de justicia, es evidente que la acción también perjudica económicamente a Santiago.

Si revisamos cuál ha sido la concepción de nuestros tribunales en la aplicación del CPP 1940, se podrá apreciar que en todos estos casos y en casos similares la noción de sujeto pasivo de la acción $\multimap$ o de sujeto pasivo del delito- de dudosa construcción conceptual suele absorber toda la discusión jurisprudencial incluso en el ámbito de la acción civil, como si solo de ello dependiera la posibilidad de ejercer una acción civil en el proceso.

En estos casos, nuestro sistema procesal penal — sobre todo en aplicación del CPP 1940 - suele impedir la participación de los perjudicados en el proceso. Por regla general, se sostiene que determinada persona no puede participar en el proceso penal si se tiene en cuenta que, atendiendo a la naturaleza del delito y al bien jurídico protegido por él, no estamos frente a una «figura» que lo «concibe» como agraviado.

En el primer ejemplo, y sobre la línea de nuestro análisis anterior, se sostendría que no existe la figura de daños culposos. Pero además se sostendrá que, ya que en este caso se ha cometido un delito contra la seguridad pública (peligro común), este se realiza en agravio de la sociedad (algunos jueces dirían, en el colmo del absurdo, un delito «contra el Estado»), mas no del particular: Pedro, dueño del garaje hecho añicos.

En el segundo ejemplo, se dirá que el bien jurídico protegido es el «normal funcionamiento de la administración pública» sin caer en cuenta que quien participa involuntariamente de un concurso fraudulento (la empresa Ultramar) se ve seriamente afectada con la violación de las «reglas del juego». No solo se perjudica el Estado, ya sea porque adquiere un bien de menor valor o calidad, ya sea porque sencillamente se violan las reglas impuestas para que la adquisición de bienes y servicios se realicen con transparencia. Evidentemente, se perjudica a aquel que participó convencido de que la licitación sería un concurso justo y que 
asumió un daño emergente y, eventualmente, un lucro cesante por la realización del hecho que constituye el objeto del proceso.

Lo mismo sucedería con el tercer ejemplo: se dirá que el fraude procesal se realiza en agravio de la administración de justicia y, por tanto, que el agraviado no puede ser un particular. Sin embargo, no se advierte que tal situación puede afectar seriamente los derechos de Santiago, que también participa en ese proceso y que, naturalmente, lo hace en el orden del cumplimiento de unas expectativas mínimas en función del respeto hacia las reglas procesales.

Sin duda, estos ejemplos también cuestionan seriamente la imagen de la acción civil desde un prisma que, evidentemente, lo confunde con el proceso penal. ¿Tiene sentido este razonamiento? A pesar de ser un razonamiento frecuentemente utilizado en el sistema procesal peruano, sí y no lo tiene.

Si se asume lo que se ha dicho hasta aquí en torno a un giro decisivo en la concepción del ejercicio de la acción civil del proceso penal, es evidente que también debe existir un cambio de hábito en el planteamiento de estos problemas. Porque si el nuevo sistema procesal penal permite que se declare la existencia de responsabilidad civil y la obligación del pago de una reparación civil por el daño causado incluso en una sentencia absolutoria o en el auto de sobreseimiento, es evidente que ello permite, sin lugar a dudas, que también se considere como perjudicado a un sujeto determinado cuando las consecuencias del objeto procesal lo perjudican.

Seguirá siendo indispensable definir quién es el sujeto pasivo de la acción o el sujeto pasivo del delito, a efectos de establecer si se cumple o no con ciertas cuestiones vinculadas al ámbito de la tipicidad y punibilidad, esto es, con situaciones que definan la existencia de responsabilidad penal de una persona. Pero estas cuestiones esencialmente penales no tienen por qué afectar la posibilidad de discutir un daño civil vinculado con la existencia de una situación concreta: que alguien destrozó mi garaje en estado de ebriedad, que mi «competidor» cometió fraude en el concurso público, que quien me demandó utilizó armas ilícitas para ganar un proceso.

Con esto no se quiere decir que el sistema procesal establezca una vía abierta para que cualquier concepto indemnizatorio pueda discutirse en la vía penal, como si de pronto esta adquiera una libertad absoluta para pronunciarse sobre conflictos netamente civiles. Desde luego, esto deberá ser resuelto al inicio de una investigación penal que solo podrá incluir hechos que constituirán luego el objeto procesal y que al menos deberán tener apariencia delictiva: no se podrá someter al conocimiento de la jurisdicción penal un hecho claramente atípico desde la perspectiva penal.

\section{LA ACCIÓN CIVIL EN EL NUEVO \\ PROCESO PENAL}

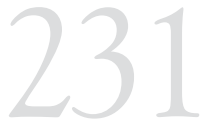


Sin embargo, que la naturaleza atípica del hecho u otro presupuesto procesal se presenten para imposibilitar la sentencia penal en el transcurso del proceso no significa que no deba declararse la responsabilidad civil que haya sido efectivamente demostrada. De la misma manera, tampoco podrá impedirse el pago de una indemnización cuando una persona lo merezca a consecuencia de un hecho comprobado judicialmente, ello independientemente de cuál sea el bien jurídico protegido, de quién sea su titular y quién el sujeto pasivo de la acción o del delito, que es como además puede ser calificado ese hecho generador de responsabilidad civil. Finalmente, este giro en la concepción debe constituir un importante factor de cambio en otros problemas fundamentales de nuestra administración de justicia penal.

Otra cambio necesario en nuestro sistema de justicia se refiere al hecho de que existe una absoluta falta de hábito en los abogados del actor civil para introducir una pretensión civil expresa, probar el daño y exigir un monto específico por concepto de indemnización en el proceso penal. En la aplicación del CPP 1940, la parte civil se ha limitado siempre a pronunciarse sobre aspectos vinculados a la responsabilidad penal que no le competen.

La participación de los abogados de la víctima en el proceso penal fundamentalmente a cargo de especialistas en Derecho penal- de nuestro actual sistema podría calificarse de paupérrima en cuanto al conocimiento, el manejo y la explicación de las reglas del Código Civil que regulan el ámbito de la definición de responsabilidad civil. Además, es usual la costumbre de realizar una sólida interpretación de temas penales que no suelen formar parte de su competencia. Hoy, si se tiene en cuenta que la sentencia condenatoria no configura un requisito de la declaración de responsabilidad civil, se manifiesta de forma mucho más intensa la obligación de los abogados del actor civil para participar en la prueba y en el discurso oral de la responsabilidad civil en el proceso penal: el NCPP deberá impulsar un cambio de hábito en ese sentido.

Por último, otro problema gravísimo de nuestra administración de justicia, también vinculado al tema tratado, radica en que la práctica judicial revela que los montos dinerarios que se establecen por concepto de daño en sede penal son en realidad ínfimos y no guardan relación con el hecho que constituye el objeto procesal ${ }^{14}$. Lo que es más grave: existe una terrible desproporción entre las indemnizaciones que se otorgan en sede civil y aquellas fijadas en un proceso penal, aun cuando se trata de hechos generadores de daños idénticos, como si de pronto el orden jurisdicción penal estuviera obligado a actuar con una benevolencia que sería inexplicable en sede civil. 
Considero que este también es un problema generado a raíz de una concepción errada de la responsabilidad civil como factor punitivo o como interés social, y es una distorsión que genera un serio riesgo para el interés del Estado de regular una acumulación de pretensiones que facilite la administración de justicia.

Este nuevo código debe constituir la piedra angular de un cambio de hábito fundamental que obligue a los actores a trabajar con las instituciones de Derecho privado y a propiciar que el orden jurisdiccional penal pueda satisfacer, con la misma seriedad que se le exige al orden jurisdiccional civil, la reparación de un daño ocasionado por el hecho que constituye el objeto del proceso. Esa es la motivación de la acumulación de acciones, no la de obtener una reparación o indemnización de menor cuantía en sede penal. Y esto solo puede ocurrir si se registra un giro sustancial en la interpretación del ejercicio de la acción civil en el proceso penal que hasta ahora ha dominado nuestra dogmática y doctrina jurisprudenciales. 